\title{
Isolation of a New Phlorotannin, Fucodiphlorethol G, from a Brown Alga Ecklonia cava
}

\author{
Young Min Ham, Jong Scok Baik, Jin Won Hyun, and Nam Ho Lee* \\ Deparmen of Chemistry and Research Instime of Basic Sciences, Cheju National Universitv, Jeju 690-756. Korea \\ E-mail: namhoiachejuac, $k$ r \\ "Department of Biochemistry. College of Medicine. Cheju National University, Jeju 690-756, Kored \\ Received March 30. 2007
}

Key Words : Phlorotannin, Fucodiphlorethol G, Seaweed, Ecklonia cava

\begin{abstract}
Ecklonia cawa is a brown alga (Alariaceae), widely distributed offshore in Jeju Island. In search of anti-oxidative and anti-tyrosinase components from natural products in Jeju, we have been working on $E$. cava.' During the phytochemical study on the methanol extract of $E$. cana, a new phlorotannin-type compound 1 , which we named fucodiphlorethol G. was isolated. Phlorotannins are oligomertic compounds using phloroglucinol (I,3,5-trihydroxybenzene) as a basic unit. Some phlorotannins have been identified as the bioactive components in Ecklonior species such as $E$. cava, ${ }^{2}$ E. ktrome ${ }^{3}$ and $E$. stolonifera. ${ }^{4}$ Described here are the isolation and structure identification of the compound 1 .
\end{abstract}

The seaweed. E. cava was collected oftshore in Jeju lsland, and air dried and cut into small pieces. The dried $E$. cava powder $(4.0 \mathrm{~kg}$ ) was extracted using $80 \% \mathrm{MeOH}$ to provide the oily material $(1.0 \mathrm{~kg})$. The extract was partitioned between water and ethyl acetate. The obtained ethyl acetate fraction was successively column chromatographed using celite and then sephadex $\mathrm{LH}-20$ to give $\mathrm{Il}$ fractions. The eighth fraction was further purified by using Prep-LC (LC-9104, JAI) system, yielded compound 1 (140 $\mathrm{mg}$ ) as off-white amorphous powder.

By analysis of the ${ }^{1} \mathrm{H}$ and ${ }^{13} \mathrm{C}$. NMR spectra in $\mathbf{1}$, only aromatic proton and carbon peaks were observed. Therefore it was tentatively assumed that this compound is a phloroglucinol oligomer, a class of common compounds detected in this alga. Further investigation of ${ }^{13} \mathrm{C}$ and DEPT NMR data suggest that $\mathbf{1}$ has a structure of phloroglucinol tetramer. The molecular formular of 1 was determined as $\mathrm{C}_{2,4} \mathrm{H}_{18} \mathrm{O}_{12}$ (unsaturation number 16) on the HR-FAB-MS data [1n/z $499.0860(\mathrm{M}+\mathrm{H})^{\prime}$, calcd for $\mathrm{C}_{21} \mathrm{H}_{1}, \mathrm{O}_{12} 499.0877, \Delta-1.7$ inmu].

However, investigation of the ${ }^{15} \mathrm{C}$ NMR spectrum showed only 20 carbon signals, which implies that two symmetric benzene units are involved in compound 1 . By the examination of ${ }^{1} \mathrm{H}$ and ${ }^{1.3} \mathrm{C}$ NMR data, it was found that structure of compound $\mathbf{l}$ is similar to that of triphlorethol-A (3), a trimeric phlorotannin previously isolated. ${ }^{\text {ld }}$ In the case of 1 , it was assumed that one additional phloroglucinol unit was attached to triphlorethol-A framework. Comparative examination of NMR $\delta$ values revealed that $\mathrm{A}$ an $\mathrm{B}$ rings in $\mathbf{1}$ are relatively unchanged compared to 3 . However, some difference was observed in $\mathrm{C}$ ring in $\mathrm{I}$. For example, ${ }^{\mathrm{H}} \mathrm{H}$ doublet at $\delta_{\mathrm{H}} 6.04\left(2 \mathrm{H}, \mathrm{H}-2^{\prime \prime}\right.$ and $\left.\mathrm{H}-6^{\prime \prime}\right)$ in 3 was converted to a doublet at $\delta_{\mathrm{H}} 6.03(\mathrm{IH}, \mathrm{H}-6 ")$ in 1 . The proton signal corresponding to $\mathrm{H}-2 "$ in 3 was disappeared. In addition, four carbon signals from symmetric $\mathrm{C}$ ring in $\mathbf{3}$ was changed to six carbon signals in $\mathbf{1}$, indicating the loss of ring symmetry. Therefore, it was clear that additional phloroglucinol unit is attached to in $\mathrm{C}$ ring at $\mathrm{C}-2^{\prime \prime}$ (or C-6") position in 3 . The attachment of additional phlorotannin unit could be made through either direct carbon-carbon or carbon-oxygen connections. Inspection of ${ }^{1} \mathrm{H}$ NMR spectrum of 1 revealed that only a singlet signal $\left(2 \mathrm{H}, \mathrm{H}-3^{\prime \prime \prime}\right.$ and $\left.\mathrm{H}-5^{\prime \prime \prime}\right)$ was appeared in $\mathrm{D}$ ring, which means that the aromatic carbon in $\mathrm{D}$ ring is directly connected to C-2" in C ring. Chemical shift of C-2" at $\delta_{C} \cdot 102.0 \mathrm{in} 1$ also supported this assignment since, if an oxygen is attached, chemical shift of $\mathrm{C}-2^{\prime \prime}$ should be shifted to $20-30 \mathrm{ppm}$ more down field compared to $\delta_{C} \cdot 102.0$.
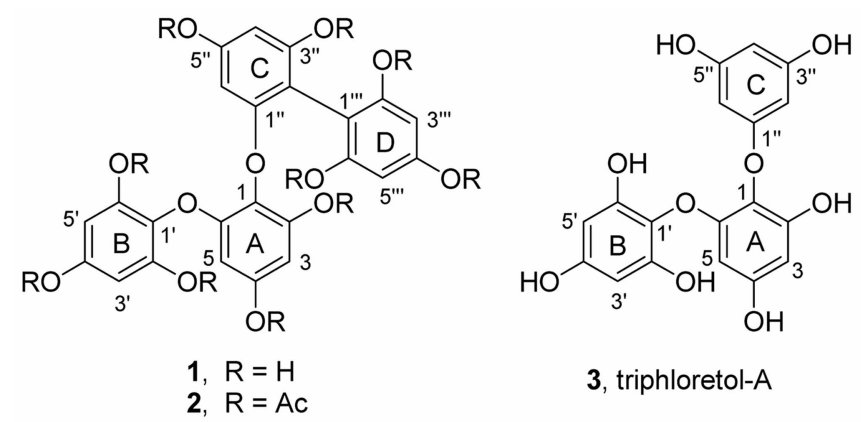

3, triphloretol-A

We also have tried to confirm the connection of C-D ring by $\mathrm{HMBC}$ long range correlation using NMR. However, we could not observe any cross peak between $\mathrm{C}$ and $\mathrm{D}$ rings in compound 1 . Therefore, we decided to prepare the peracetylated compound $\mathbf{2}$. The compound $\mathbf{2}$ was prepared by the treatment of acetic anhydride and pyridine, and its NMR data is also summarized in Table 1. In contrast to the case of 1, the synthetic derivative $\mathbf{2}$ provided desired $\mathrm{HMBC}$ ? correlation data. Unusually long range ${ }^{5} J_{\mathrm{CH}}$ connectivity between $\mathrm{H}-6^{\prime \prime}$ and $\mathrm{C}-2^{\prime \prime \prime}$ (and $\mathrm{C}^{\prime}-6^{\prime \prime}$ ) was appeared in 2. Presumably, this observation was possible due to the conjugated $\pi$-system in the C-D ring.

In the case of acetylated phlorotannins, Glombitza has reported a structure prediction method based on calculated ${ }^{1:} \mathrm{C}$ NMR data considering their substitution types and steric effects around aromatic rings." When this protocol was 
Table 1. Comparative NMR data for compounds 1, 2 and 3

\begin{tabular}{|c|c|c|c|c|c|c|c|}
\hline \multirow[b]{2}{*}{ no. } & \multicolumn{2}{|r|}{$1^{\prime \prime}$} & \multicolumn{3}{|c|}{$2^{k}$} & \multicolumn{2}{|r|}{$3^{a}$} \\
\hline & $\dot{S}$ & $\delta_{11}($ mult.,$f$ in $\mid \mathrm{I} \%)$ & $\delta$ & $\delta_{11}$ (mult. $f$ in I l $x$ ) & $\begin{array}{l}\mathrm{HMBC}^{\prime} \\
(\mathrm{H} \rightarrow \mathrm{C})\end{array}$ & $\delta_{i}$ & $\delta_{\mathrm{Ll}}(\mathrm{m} \mathrm{m} \mathrm{l} \mathrm{L} . /$ in $\mathrm{I} \%)$ \\
\hline 1 & 124.9 & - & 133.4 & - & - & 127.5 & - \\
\hline 2 & 157.5 & - & 144.2 & - & - & 152.7 & - \\
\hline 3 & 98.0 & $5.69(\mathrm{~d} .2 .7)$ & 108.5 & $6.40($ d. 2.6$)$ & $C-1 . C-5$ & 98.0 & $5.78(\mathrm{~d} .2 .7)$ \\
\hline 4 & 153.7 & - & 147.5 & - & - & 156.1 & \\
\hline 5 & 94.5 & $6.02($ d. 2.7$)$ & 112.1 & 6.67 (d. 2.6$)$ & $C-1 . C-3$ & 94.9 & 6.09 (d. 2.9) \\
\hline 6 & 152.0 & - & 149.9 & - & - & 153.7 & - \\
\hline $1^{\prime}$ & 124.3 & - & 136.6 & - & - & 124.6 & - \\
\hline $2^{\prime}$ & 152.1 & - & 143.8 & - & - & 152.1 & - \\
\hline $3^{\prime}$ & 96.0 & $5.91(\mathrm{~s})$ & 115.1 & $6.85(s)$ & $C-1: C-5^{r}$ & 96.2 & $5.93(\mathrm{~s})$ \\
\hline $4^{\prime}$ & 157.9 & - & 146.9 & - & - & 156.4 & - \\
\hline $5^{\prime}$ & 96.0 & $5.91(\mathrm{~s})$ & 115.1 & $6.85(s)$ & C-1. C.-3' & 96.2 & $5.93(\mathrm{~s})$ \\
\hline $6^{\prime}$ & 152.1 & - & 143.8 & - & - & 152.1 & - \\
\hline $1^{\prime \prime}$ & 159.4 & - & 156.6 & - & - & 162.4 & - \\
\hline $2^{\mu}$ & 102.0 & - & 112.2 & - & - & 95.4 & $6.04(\mathrm{~d} .2 .2)$ \\
\hline $3^{\prime \prime}$ & 159.2 & - & 151.3 & - & - & 160.3 & - \\
\hline $4^{\prime \prime}$ & 97.5 & $6.10($ d. 2.2$)$ & 104.8 & $6.30(\mathrm{~d} .2 .2)$ & $C-2^{\prime \prime} \cdot C-6^{\prime \prime}$ & 97.5 & $5.98($ t. 2.2$)$ \\
\hline $5^{\prime \prime}$ & 159.5 & - & 150.5 & - & - & 160.3 & - \\
\hline $6^{\prime \prime}$ & 94.3 & 6.03 (d. 2.2$)$ & 110.7 & $6.70(\mathrm{~d} .2 .2)$ & $\mathrm{C}-2^{\prime \prime} \cdot \mathrm{C}-4^{\prime \prime} \cdot \mathrm{C}-2^{\prime \prime \prime} \cdot \mathrm{C}-6^{\prime \prime \prime}$ & 95.4 & 6.04 (d. 2.2 ) \\
\hline $1^{\text {trt }}$ & 101.8 & - & 116.0 & - & - & & \\
\hline $2^{\prime \prime \prime}$ & 156.3 & - & 149.8 & - & - & & \\
\hline $3^{\prime \prime \prime}$ & 96.4 & $6.05(\mathrm{~s})$ & 113.8 & $6.90(s)$ & $\mathrm{C}-1^{\prime \prime \prime} \cdot \mathrm{C}-5^{\prime \prime \prime}$ & & \\
\hline $4^{\prime \prime \prime}$ & 159.2 & - & 151.0 & - & - & & \\
\hline $5^{\prime \prime \prime}$ & 96.7 & $6.05(\mathrm{~s})$ & 113.8 & $6.90(\mathrm{~s})$ & $C-1^{\prime \prime \prime} . C-3^{\prime \prime \prime}$ & & \\
\hline $6^{1+1}$ & 156.3 & - & 149.8 & - & - & & \\
\hline
\end{tabular}

"Recorded in $\mathrm{CD}_{3} \mathrm{OD}$. "Recorded in $\mathrm{CDCl}$;

subjected to 2, experimental $\delta_{c}$ values for 2 were well matched to the calculated $\delta_{\mathrm{C}}$ values, i.e. the difference between the values were within $3.2 \mathrm{ppm}$ range for all carbons.

The nomenclature system for the marine phlorotannins was originally introduced by Glombitza. According to this system, tetrameric phlorotannins $\left(\mathrm{C}_{24}\right)$ composed of difucol

Table 2. Analysis of fucodiphlorethols A-F based on their connection pattem between difucol and diphlorethol

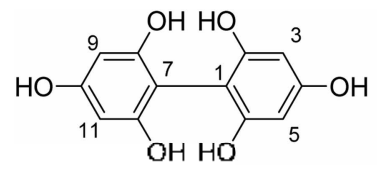

Difucol

\begin{tabular}{ccc}
\hline \multirow{2}{*}{$\begin{array}{c}\text { Fucodiphlorethol } \\
\left(\mathrm{C}_{2-1}\right)\end{array}$} & \multicolumn{2}{c}{ Atoms contected each other } \\
\cline { 2 - 3 } $\mathrm{A}$ & Difucol $\left(\mathrm{C}_{12}\right)$ & Diphlorthol $\left(\mathrm{C}_{12}\right)$ \\
\hline $\mathrm{C} 3$ & $\mathrm{O}-4$ & $\mathrm{C}-10$ \\
$\mathrm{C}$ & $\mathrm{C}-3$ & $0-2$ \\
$\mathrm{I})$ & $\mathrm{C}-3$ & $0-9$ \\
$\mathrm{E}$ & $\mathrm{C}-3$ & $0-4$ \\
$\mathrm{H}$ & $\mathrm{O}-2$ & $\mathrm{C}-8$ \\
& & $\mathrm{C}-10 . \mathrm{C}-10$
\end{tabular}

"C-10 of diphlorethol is coupled each other to form a dimer.
$\left(\mathrm{C}_{12}, \mathrm{C}_{6}-\mathrm{C}_{6}\right.$ form) and diphlorethol $\left(\mathrm{C}_{12}, \mathrm{C}_{6}-\mathrm{O}-\mathrm{C}_{6}\right.$ form $)$ are named as fucodiphlorethol. In the literature, six different types of fucodiphlorethols, named fucodiphlorethol A-t; have been isolated and characterized in the form of acetylated derivatives. ${ }^{6}$ For example, in the case of fucodiphlorethol $\mathrm{A}\left(\mathrm{C}_{24}\right), \mathrm{O}-4$ in difucol $\left(\mathrm{C}_{12}\right)$ is connected to $\mathrm{C}-10$ in diphlorethol $\left(\mathrm{C}_{12}\right)$. The same analysis can be applied to the other fucodiphlorethols (see Table 2). In the case of phlorotannin 1 , we can describe that $\mathrm{O}-2$ in difucol $\left(\mathrm{C}_{12}\right)$ is coupled to $\mathrm{C}-8$ in diphlorethol $\left(\mathrm{C}_{12}\right)$. It is clear that this connection pattern is different from the previous known fucodiphlorethols A-F. Thus, new phlorotannin $\mathbf{1}$ is named as fucodiphlorethol $\mathrm{G}$.

In conclusion, we have isolated a new compound $\mathbf{1}$ from the methanol extract of Ecklonia cova, a brown alga collected offshore in Jeju Island. The tetrameric phlorotannin 1, named fucodiphlorethol $\mathrm{G}$, has strong radical scavenging effect $\left(\mathrm{JC}_{5} 0.60 \mu \mathrm{M}\right)$ on the DPPH test. ${ }^{7}$

\section{Experiment Section}

Reagent and Equipment. Thin layer chromatography was performed on Merck prepared plates (silica gel $60 \mathrm{H}$ 254 on aluminum). Column chromatography was performed using Merck silica gel 60 (230-400 mesh). Sephadex LH-20 $(25-100 \mu \mathrm{m})$ for Gel filtration chromatography $(\mathrm{GHC})$ was 
obtained from Fluka. The UV absorbance was perforned with a Biochrom Libra \$22 UV-visible spectrophotometer. ${ }^{1} \mathrm{H}(400 \mathrm{MHz})$ and ${ }^{13} \mathrm{C}(100.60 \mathrm{MHz}) \mathrm{NMR}$ spectra were recorded on a JEOL, JNM-LA 400 instrument, with chemical shift data reported in ppm relative to the solvent used. 2D NMR spectra were recorded on the same instrument using field gradient FG2 (inverse) probe. HPLC separation was performed using LC-9140 (JAI) equipped with ODScolumn. General laboratory solvents were distilled from glass before use.

Isolation of Compound 1. The seaweed. $E$. concr was collected in the seashore of Gvideog-ri, Jeju Island. and air dried and cut into small pieces.

The dried $E$. con a powder $(4.0 \mathrm{~kg})$ was suspended in $16 \mathrm{~L}$ of $80 \% \mathrm{MeOH}$ and mechanically stirred for $24 \mathrm{~h}$ at room temperature. The solution was filtered and the filtrate was concentrated under reduced pressure to give the oily extract $(1.0 \mathrm{~kg})$. After the extract was suspended on $1 \mathrm{~L}$ of distilled water, organic soluble fraction $(220 \mathrm{~g})$ was obtained by treating ethyl acetate. The obtained ethyl acetate fraction was poured in a celite column $(5 \mathrm{~cm} \times 40 \mathrm{~cm})$. and the column was sequentially eluted with $n$-hexane $(3 \mathrm{~L}) . \mathrm{CH}_{2} \mathrm{Cl}_{2}$ $(6 \mathrm{~L})$, diethyl ether $(9 \mathrm{~L})$ and methanol $(5 \mathrm{~L})$. Based on NMR analysis. phlorotannins were observed in diethyl ether fraction $(\mathrm{l} 4 \mathrm{~g})$, which was further purified by sephadex LH. 20 column chromatography using stepwise gradient $\mathrm{CHCl}_{3} /$ methanol $(2 / 1$ to $L / 1$ to $0 / 1)$ solvents system to give 11 fractions based on TLC analysis. The compound 1 ( $1+0 \mathrm{mg})$ was obtained by further purification of the fraction $8(514$ mg) using Prep-LC (LC-9104, JAI) system equipped with ODS column in methanol solvent.

Fucodiphloretho $\mathrm{G}$ (1). Off-white powder: UV $\left(\mathrm{CH}_{3} \mathrm{OH}\right)$ $280(\varepsilon 32.500) 269(\varepsilon$ 8.000); HR-FAB-MS data $[\mathrm{m} / \mathrm{z}$ $499.0860(\mathrm{M}+\mathrm{H})^{-}$, calcd for $\mathrm{C}_{2}+\mathrm{H}_{19} \mathrm{O}_{12}$ 499.0877. $\Delta-1.7$ mniu]. For ${ }^{1} \mathrm{H}$ and ${ }^{13} \mathrm{C}$ NMR data. see Table $\mathrm{I}$.

Acetylation of Compound 1. In a vial were placed the compound $1(52 \mathrm{mg})$, pyridine $(\mathrm{lmL})$ and acetic anlydride $(1 \mathrm{~mL}$ ). After the resulting mixture was stirred for $4 \mathrm{~h}$ at $\mathrm{rt}$. the solutuion was partitioned between chloroform and water.
The chloroform layer was concentrated, and purified using short path $\mathrm{SiO}_{2}$ column chromatography to give decaacetylated $2(7.1 \mathrm{mg})$. For ${ }^{1} \mathrm{H}$ and ${ }^{13} \mathrm{C}$ NMR data. see Table 1 . Proton NMR peaks for the acetyl groups are showing up at $\delta_{\mathrm{H}} 2.2 \mathrm{l}(3 \mathrm{H}) .2 .20(3 \mathrm{H}), 2.16(3 \mathrm{H}) .2 .13(3 \mathrm{H}), 2.08(3 \mathrm{H})$, $1.90(3 \mathrm{H}) .1 .89(6 \mathrm{H}), 1.80(3 \mathrm{H}) .1 .50(3 \mathrm{H})$. Due to peak overlap, only six ${ }^{13} \mathrm{C}$ peaks for the $\mathrm{C}=\mathrm{O}$ in the actyl groups are appeared at $\delta_{\subset} 168.8,168.7,168.6 .168 .4 .168 .2 .168 .1$ ppm.

Acknowledgment. This research was performed under the program of Basic Atomic Energy Research Institute (BAERI) which is a part of the Nuclear R\&D Programs funded by the Ministry of Science \& Teclunology (MOST) of Korea.

\section{References}

1. (a) Kiml. T.-A.: Lee. T.-M.: Lee. N. H. Food Sci. Biotechnol 2004. 13. 476. (b) Kang. K. A.: Lee. K. H.: Chae. S.-W.: Koh. Y. S.: Yœ. B.-S.: Kim. T. H.: Ham. Y. M.: Baek. J. S.: Lee. N. H.: Hyun. J. W. Free Radical Research 2005. 39. 883. (c) Kang, K. A.; Chae. S.-W.: Lee. K. H.: Zhang, R.: Jung. M. S.: Kim, S. Y; Kim. H. S.: Joo. H. G.: Park. J. W.: Ham, Y. M.: Lee. N. H.: Hyun. J. W. FEBS Lenters 2005. 579. 6295. (d) Bu. H.-T.: Ham. Y. M.: Kiml. J. M.: Lee. S.-T.: Hyut. J. W.: Lee. N. H. Kon J. Phamacogn. 2006. 37.92

2. Ahn. M. J: Yoon, K. D.; Min, S. Y : Lee, J. S.: Kim. J. H. Kim, T. G.; Kim. S. H.; Kim, N. K.; Huh, H.: Kim. J. W. Biol. Pham Bull. 2004. 27, 54t.

3. (a) Fukityama. Y.: Komada. M.: Miura. I.: Kinzyo. Z.: Kido. M: Mori. H.: Nakyama. Y: Takahashi. M. Chent Phorm. Bull. 1989. 37. 349.

4. Kang. H. S.; Chung. H. Y.: Jung, J. H.: Son. B. W. Chem. Pham. Bull. 2003, 51,1012 .

5. Wegner-Hambloch, S.; Glombitza, K. W. Magnetic Resonance in Chentistry 1985.23.358.

6. (a) Glombitza. K. W. In Marine Natural Product Chemistr: Faulkiter. D. J: Fenical. W. H.. Eds.: Plenum Press: New York. 1977: p 191. (b) Ragan, M. A.; Glombitza, K.-W., In Progess in Phycological Research; Round. F. E.; Chapman. D. J.. Eds: Biopress: Bristol, 1986; Vol. 4: p 129.

7. Blois. M. S. Nattre 1958. 181. 1199. 